\title{
Ultra-Early Optic Nerve Decompression for the Resection of Anterior Clinoidal Meningioma
}

\author{
Soichi Oya ${ }^{1}$ Toru Matsui ${ }^{1}$ \\ ${ }^{1}$ Department of Neurosurgery, Saitama Medical Center, Saitama \\ Medical University, Saitama, Japan
}

J Neurol Surg B 2018;79(suppl S2):S231-S232.

\begin{abstract}
Address for correspondence Soichi Oya, MD, PhD, Department of Neurosurgery, Saitama Medical Center, 1981 Kamoda, Kawagoe, Saitama 350-8550, Japan (e-mail: sooya-tky@umin.ac.jp).
\end{abstract}

\begin{abstract}
Keywords

- meningioma

- anterior clinoid

- optic nerve

- decompression

- visual recovery

Improvement in vision is one of the main goals of surgery for anterior clinoidal meningiomas with visual deficits. Early optic nerve decompression surgery has been advocated in previous studies to achieve the best visual outcome. Through this video, the authors describe their surgical techniques to decompress the optic nerve at the very early stage of surgery.

A 35-year-old patient presented with subjective blurry vision in the right eye over the last 8 months. Magnetic resonance images showed a 3.2-cm meningioma arising at the right anterior clinoid. Preoperative ophthalmological test was within the normal range, but the patient wished to have surgical resection after a detailed discussion of benefits and risks related to surgical resection. The surgical strategy consisted of the right lateral subfrontal approach that includes a standard right frontotemporal craniotomy, extradural anterior clinoidectomy, and early optic nerve decompression prior to tumor resection. The tumor was divided into compartments defined by the arteries and resected. Simpson grade II resection was achieved without complications. The patient's symptoms disappeared.

In anterior clinoidal meningiomas that cause visual deficits, the optic nerve is assumed very vulnerable to any further injuries related to the operative maneuver. Ultra-early optic nerve decompression can be performed in anterior clinoidal meningiomas regardless of their size by extradural unroofing of the optic canal and sectioning of the optic canal sheath, which we believe contributes to better visual improvement. The link to the video can be found at: https://youtu.be/RIFi4ecWAhQ.
\end{abstract}

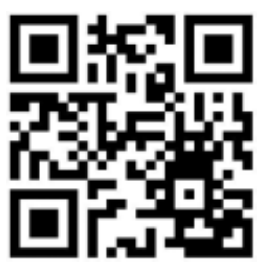

received

October 14, 2017 accepted

December 7, 2017

published online

January 18, 2018

www.thieme.com/skullbasevideos

www.thieme.com/jnlsbvideos

DOI https://doi.org/

10.1055/s-0038-1623521. ISSN 2193-6331.
๑) 2018 Georg Thieme Verlag KG
Stuttgart · New York

License terms

(c) (1) $\ominus$ (\$) 

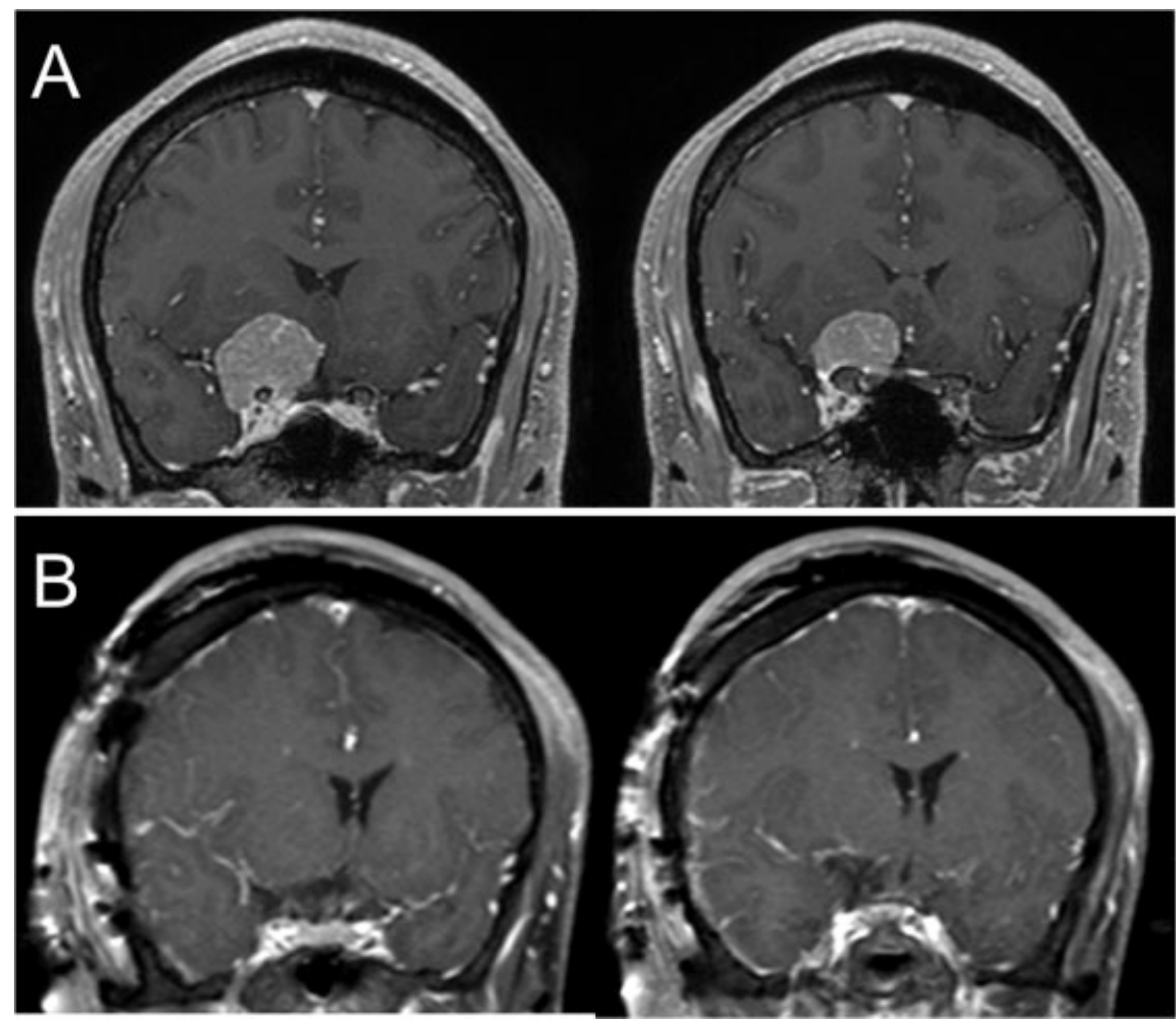

Fig. 1 (A) Coronal magnetic resonance (MR) images demonstrating a right anterior clinoidal meningioma with the hypertrophied anterior clinoid. (B) Coronal MR images obtained postoperatively showing gross total resection.
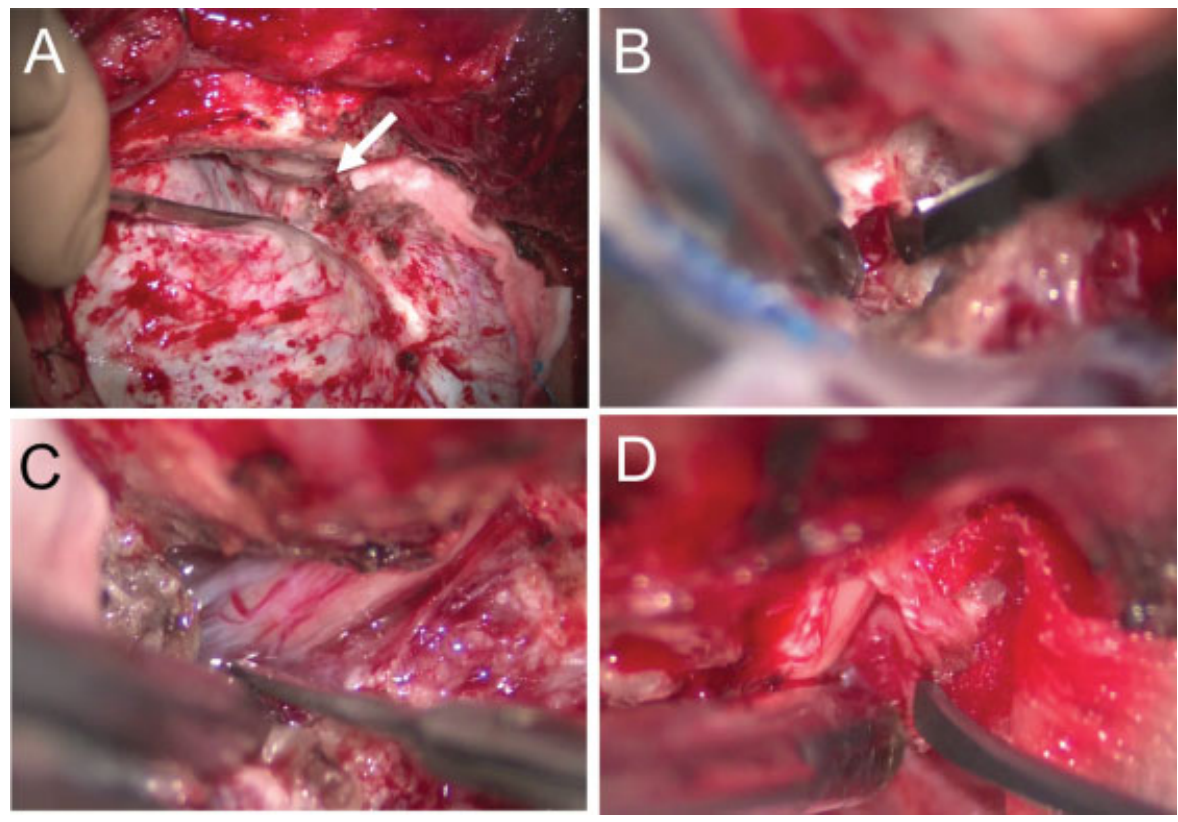

Fig. 2 Intraoperative views showing a wide extradural space (arrow) by aggressive drilling of the sphenoid bone and flattening of the anterior cranial base (A), optic sheath opening (B), and dissecting the tumor from the optic nerve (C) before tumor debulking, and complete resection of the tumor invading the optic canal (D). 